\title{
Gambling and Impulsivity: An Exploratory Study in a French Adolescent Population
}

\author{
Lucia Romo ${ }^{1 *}$, Gayatri Kotbagi1 ${ }^{1}$, Sophie Platey ${ }^{1}$, Adelaide Coeffec ${ }^{1}$, Francesco Boz ${ }^{1}$, \\ Laurence Kern ${ }^{2}$ \\ ${ }^{1}$ Laboratoire EA 4430-CLIPSYD, Université Paris Ouest Nanterre La Défense, Nanterre Cedex, France \\ 2Laboratoire EA 2931, Centre de Recherches sur le Sport et le Mouvement-CERSM, Université Paris Ouest La \\ Défense, Nanterre Cedex, France \\ Email: Iromosdes@u-paris10.fr
}

Received 26 May 2014; revised 26 June 2014; accepted 10 July 2014

Copyright (C) 2014 by authors and Scientific Research Publishing Inc.

This work is licensed under the Creative Commons Attribution International License (CC BY).

http://creativecommons.org/licenses/by/4.0/

(c) (i) Open Access

\begin{abstract}
Pathological gambling can be a serious problem, more so to a vulnerable population such as adolescents and youth. This study aims to investigate the links between gambling behaviours and impulsivity through a multidimensional approach in a French adolescent population. A secondary aim of this study is to find out the prevalence of pathological gambling behaviour amongst adolescents who are not meant to have legal access to such games. We administered the UPPS Impulsive behaviour Scale (UPPS-P) and the Canadian Pathological Gambling Index CPGI to 1800 adolescents aged between 11 to 17 years. Our results indicate that $33 \%$ of subjects have gambled at least once during the last year and that girls gamble as much as boys $(17 \%$ and $16 \%$ respectively). Scratch games are the most common games played by adolescents $(81.4 \%)$. We also notice that $1.6 \%$ of our population has problematic gambling behaviour. Although we found that many dimensions of impulsivity (Urgency, Positive urgency and Sensation seeking) are correlated to gambling behaviour, only sensation seeking seems to be a good predictor of pathological gambling severity. These results can be taken into account in the development of prevention programs.
\end{abstract}

\section{Keywords}

Impulsivity, Adolescents, Prevalence, Pathological Gambling

\section{Introduction}

Numerous studies indicate that gambling is widespread amongst youngsters including juveniles [1]-[4].

"Corresponding author.

How to cite this paper: Romo, L., Kotbagi, G., Platey, S., Coeffec, A., Boz, F. and Kern, L. (2014) Gambling and Impulsivity: An Exploratory Study in a French Adolescent Population. Open Journal of Medical Psychology, 3, 306-313.

http://dx.doi.org/10.4236/ojmp.2014.34032 
According to the INSEE, in 2006, approximately 30 million people have gambled at least once in France. In addition, according to the "Observatoire Français des Drogues et des Toxicomanies" (OFDT) which is the French Monitoring Centre for Drugs and Drug Addiction [5], approximately one out of two individuals (47.8\%) aged between 18 - 75 years have declared to have been gambling during the last year with the Act of 12 May 2012 (La loi du 12 mai 2010), online gambling has boomed exponentially. However, for certain individuals the game could become excessive, intrusive and uncontrollable and may create problems at individual, family, academic or professional levels and take form of an addictive behaviour [6]-[8].

Gupta and Derevensky [1] who studied pathological gambling, stressful events and coping strategies in 2156 adolescents aged between 11 - 20 years found (despite the prohibition of play forminors) high levels of gambling behaviour in these adolescents: $63 \%$ of players of which $23 \%$ were weekly players and $2.7 \%$ were potential pathological gamblers. Shaffer et al. [9] identified 160 prevalence studies in North America and were able to highlight a mean prevalence of $14.6 \%$ of problem gamblers and $4.8 \%$ of pathological gambler sinadolescent population. A meta-analysis of Blinn-Pike, Worthy and Jonkman [10] suggests a 7.89\% of pathological gambling in adolescent population. In Europe, very few studies have been conducted.

In Iceland, Thor Olason, Sigurdardottir and Smari [11] showed respectively 2\% to 2.7\% of problem gambling depending on the scale used in750 subjects aged between 16 and 18 years. A study in UK by Fisher [12] found $5.6 \%$ of prevalence of problem gambling in 9774 subjects aged between 12 and 15 years, however, without distinguishing between pathological gambling and problematic gambling.

Pathological gambling (PG) has been classified as an impulse control disorder in the Diagnostic and Statistical Manual for Mental Disorders-DSM-5 [13]. PG is said to be included in the "Substance Use and Addictive Disorders" category; (www.dsm5.org). According to the American Psychiatric Association, this change has been undertaken because various studies show that gambling activates the reward systems of the brain and produces effects similar to drug behaviours.

Legally, even if gambling is reserved only for majors, research since the early 90s suggests that adolescents have access to and are therefore, by extension, also affected by PG [1] [4] [14]-[16].

PG amongst adolescents is a public health issue [1] [9] [17]-[19]. It has been highlighted in a French general population [6] [7] [20], but remains unclear amongst the French adolescent population. Recently, Raisamo et al., [21] in a study in Britain, showed that $28.2 \%$ of boys and $12.7 \%$ of girls had played chance games and gambled during the past week. In a study on the prevalence of behavioural addictions, Villella, Martinotti et al., [22] found $7 \%$ of pathological gamblers among a sample of 2853 Italian adolescents and young adults. Problematic gambling was more amongst boys $(9.7 \%, p<0.001)$ than girls $(2.9 \%, p<0.001)$.

Impulsivity is at the core with respect to the definition of pathological gambling. Resulting in difficulty in self-regulation, it has on numerous occasions been scientifically correlated with pathological gambling [8] [23] [24] and has been recognized as a predictor of severity of pathological gambling [25]-[28]. Recent studies using longitudinal designs suggest a causal role between impulsivity and pathological gambling [29].

Researchers have long been trying to characterize individual variations in impulsivity. To date, impulsivity is defined by the categories of personality dimensions and behaviour with response inhibition and impulsive decision-making [29].

According to Barratt [30], there are three subtypes of impulsive behaviour, motor (acting without thinking), non-planning (focusing attention on the details), and attention (how deal with problem situations).

Impulsive decision-making, integrated in a cognitive-behavioural approach, is defined by the principle of behavioural economics. Thus an individual prefers an immediate reward that could have negative long-term effects, to a delayed reward probably having more positive effects. This principle of impulsive decision applies in particular to addictive behaviours [29].

In our study, we applied the multidimensional model of impulsivity proposed by Whiteside and Lynam [31]. Urgency (tendency to experience strong impulses, often accompanied by negative affect), lack of premeditation (difficulty to understand and think about the consequences of an act before doing so), lack of perseverance (inability to concentrate on a difficult task) and sensation seeking (engaging in exciting activities and being open to trying new experiences that can be dangerous) are the components of impulsivity.

A fifth dimension called positive urgency has later been demonstrated [32]. Positive urgency is the tendency to express strong reactions in extremely positive emotional contexts.

The aim of this study is to investigate the relationship between PG and impulsivity through its five facets in an adolescent population. 


\section{Method}

Data was collected during an exploratory survey conducted by the research laboratory in clinical psychology from the Paris West University Nanterre La Défense (EA Clipsyd 4430) on well-being and addictive behaviours in adolescents and young adults (between 2012 and 2013).

1800 minors were recruited between November 2011 and April 2013 in four colleges and six schools in Ile de France who agreed to participate in the research.

Finally, efforts were made to take into account the representation of all departments of the Parisian region. Subjects completed a self-administered questionnaire including socio-demographic questions (age, sex, grade), the CPGI [33] and the UPPS-P [34], to measure the variables of interest here. All the participants were clearly informed about the study. An authorisation from the parents was asked to those who agreed to participate in the study. They study followed the rules and regulations established by the ethical committee of Paris West University Nanterre La Défense, UFR SPE (Department of Psychology and Education).

\subsection{Instruments}

\subsubsection{Gambling Behavior}

Data on gambling behaviour was collected using the CPGI (Canadian Problem Gambling Index). It detects problem gamblers in the general population. Developed in the early 2000s by a Canadian team [16], it focuses on the problems and consequences related to gambling and allows a measure of intensity for each item. It establishes the following typology: "gambler without problem” (score $=0$ ), "low risk gambler" (score = 1 - 2), "moderate risk gambler" (score = $3-7$ ) and "pathological gambler" (score $=8$ or more). An intial validation of the scale demonstrated a unidimensional structure with a good internal consistency $(\alpha=0.84)$ and a satisfactory test-retest score $(r=0.78)$. This questionnaire was accompanied by a list of chance games (slots, scratch cards and rapido, PMU, online gambling, online poker and other games of chance and money).

\subsubsection{Impulsivity}

Impulsivity was measured using the UPPS (UPPS Impulsive Behavior Scale), a questionnaire developed and validated by Whiteside and Lynam [31] and validated in the French version by Vander Linden et al. [35]. This questionnaire is based on the theoretical concept of impulsivity distinguishing four dimensions of impulsivity, urgency having two subtypes (positive/negative), lack of premeditation, lack of perseverance, and sensation seeking. The psychometric qualities of the scale are satisfactory (internal consistency between 0.70 to 0.84 and test-retest score between 0.84 to 0.92 ). We use the short French version-the UPPS-P validated by Billieux et al. [34] with a population of subjects aged 17 - 50 years. According to these authors the four factor model of impulsivity does not involve the variations in impulsivity, but highlights the distinct personality traits that contribute to impulsive behavior.

\subsection{Statistical Analyses}

The statistical sample is composed of different number of subjects according to the dependent variables observed. Therefore of 1800 subjects1196 completed both the CPGI and the urgency facet of the UPPS; 1192 subjects completed both the CPGI and the positive urgency facet of the UPPS; 1171 subjects completed the CPGI and the lack of premeditation facet of the UPPS; 1187 subjects completed the CPGI and lack of perseverance facet of UPPS and finally 1155 subjects completed both the CPGI and sensation seeking facet of UPPS.

The correlations between the dependent variable, i.e. the score on the CPGI, and the independent variables, i.e. the scores on various facets of UPPS were tested with the Bravais Pearson correlations test. To clarify the relationship between different scales and subscales, we performed linear regressions through ANOVA using SPSS V20 software.

\section{Results}

The subjects were students in classes ranging from the 7th to BTS (equivalent to the Associate Degree) with an average age of 15.2 years (SD: 1.46 ), with $47.7 \%$ boys and 52.3\% girls. Table 1 gives the distribution of the population with respect to their class.

Of all the subjects who responded, 33\% reported having had at least one episode of gambling of which $48.5 \%$ 
Table 1. Distribution of population with respect to their class.

\begin{tabular}{cccccc}
\hline & \multicolumn{2}{c}{ Total } & \multicolumn{2}{c}{ Boys } & \multicolumn{2}{c}{ Girls } \\
\cline { 2 - 6 } Academic Level & $\%$ & $\%$ & Age (SD) & $\%$ & Age (SD) \\
\hline 7th Grade & 7.5 & 60.2 & $12.28(0.53)$ & 39.8 & $12.19(0.44)$ \\
8th Grade & 14.1 & 47.2 & $13.42(0.63)$ & 52.8 & $13.45(0.67)$ \\
9th Grade & 1.7 & 33.3 & $14.60(0.70)$ & 66.7 & $14.75(1.02)$ \\
10th Grade & 43.6 & 46.2 & $15.50(0.65)$ & 53.8 & $15.42(0.63)$ \\
11th Grade & 28.6 & 46.1 & $16.36(0.68)$ & 53.9 & $16.27(1.10)$ \\
12th Grade & 4.5 & 63.8 & $16.96(0.20)$ & 36.3 & $19.97(0.19)$ \\
\hline
\end{tabular}

were boys and 51.5\% were girls. Gambling behavior which was most frequently initiated in boys as well as girls was that of scratch games or rapido. Thus, $73.3 \%$ of boys and $88.1 \%$ girls prefer these types of games. Moreover, $19 \%$ of boys and $20.6 \%$ of girls haves played slot machines and $21.5 \%$ of boys and $6.3 \%$ of girls have played online poker.

Of 1356 subjects who responded to the CPGI (Table 2), 1.6\% indicate a problematic gambling behavior with a majority of males (2.7\% of boys who responded against $0.6 \%$ of girls).

If we first observe the interactions between the different dimensions of the UPPS, we can notice that most of them are strongly correlated (Table 3). Only "lack of premeditation” and "sensation seeking” are weakly correlated.

Moreover, we note that only the dimensions "Lack of premeditation" ( $r=0.044)$ and "Lack of perseverance” ( $r=0.038)$ are not correlated with the CPGI. The facet of "Urgency" of the UPPS is significantly correlated to the CPGI at $p<0.05(\mathrm{r}=059)$ whereas the facets "Positive Urgency" $(\mathrm{r}=0.081)$ and "Sensation seeking" ( $\mathrm{r}=$ $0.086)$ are strongly correlated to the CPGI $(p<0.01)$ (Table 3$)$.

The percentage of variance explained by the independent variables is $0.012(1.2 \%)$. The ANOVA (D = 2.516, $p=0.028$ ) indicates that the model is significant.

However, if we look at each independent variable in detail, only the facet of "sensation seeking" has a significant weight on the CPGI score $(\beta=088, p=0.010)$. This means that only the facet of "sensation seeking” predicted the score on the CPGI significantly.

\section{Discussion}

This research aims to study the concept of impulsivity, through its five dimensions and their role in gambling behaviours in a French adolescent population using the UPPS and the CPGI.

In fact, as expected we do not find a significant correlation between "Lack of premeditation" and the scores of CPGI.

However, amongst the five dimensions of impulsivity, we observe a significant correlation between the "Urgency" dimension of impulsivity and the scores of CPGI. This result is consistent with those of previous studies on the subject of compulsive shopping [27] [36], which showed a positive correlation between the so-called "addictive” behaviours (pathological shopping, abusive use of phone behavior and problems related to internet use) and the dimension of "Urgency" impulsivity. Pathological gambling is also a behavioral addiction, and thus, we were able to hypothesize that similar results could be observed. The CPGI is also correlated with positive urgency.

Finally, regarding the "sensation seeking" dimension, our results indicate that this dimension is not only significantly correlated to the CPGI score, but it is the only predictor of the CPGI score [37]. Our results are in line with most research in this field, according to which pathological gamblers have higher scores on sensation seeking dimension than subjects of the control group [23] [38] [39]. It is also observed that there is positive correlation between the sensation seeking facet and the intensity of pathological gambling [32] [39].

However, we do know that the "sensation seeking" dimension is negatively correlated with age, [40] supporting the idea that adolescents are more likely to engage in exciting behaviors and be open to trying new experiences, which could be dangerous. 
Table 2. CPGI scores with respect to sex.

\begin{tabular}{|c|c|c|c|c|c|c|}
\hline & & & \multicolumn{4}{|c|}{ CPGI } \\
\hline & & & No Problem & Low Risk & Moderate Risk & Problem \\
\hline \multirow{4}{*}{ Sex } & \multirow{2}{*}{ Boys } & $\mathrm{N}$ & 627 & 63 & 34 & 20 \\
\hline & & $\%$ & $84.3 \%$ & $8.5 \%$ & $4.6 \%$ & $2.7 \%$ \\
\hline & \multirow{2}{*}{ Girls } & $\mathrm{N}$ & 729 & 66 & 16 & 5 \\
\hline & & $\%$ & $89.3 \%$ & $8.1 \%$ & $2.0 \%$ & $0.6 \%$ \\
\hline \multirow{2}{*}{\multicolumn{2}{|c|}{ Total }} & $\mathrm{N}$ & 1356 & 129 & 50 & 25 \\
\hline & & $\%$ & $86.9 \%$ & $8.3 \%$ & $3.2 \%$ & $1.6 \%$ \\
\hline
\end{tabular}

Table 3. Bravais Pearson correlations between the CPGI and five facets of UPPS.

\begin{tabular}{ccccccc}
\hline & ICJE-Tot & Urg & Urg+ & Premed & Persev & Sseek \\
\hline Urg & $0.059^{* *}$ & & & & \\
Urg+ & $0.081^{* *}$ & $0.547^{* *}$ & & & \\
Premed & 0.044 & $0.177^{* *}$ & $0.162^{* *}$ & & \\
Persev & 0.038 & $0.060^{*}$ & -0.046 & $0.396^{* *}$ & \\
Sseek & $0.086^{* *}$ & $0.211^{* *}$ & $0.406^{* *}$ & $0.033^{*}$ & $-0.129^{* *}$ & \\
\hline
\end{tabular}

*Significant correlation at 0.05 (bilateral); ${ }^{* *}$ Significant correlation at 0.01 (bilateral). Urg: Urgence, Urg+: Urgence positive, Premed: Lack of Premeditation, Persev: Lack of Perseverance, Sseek: Sensation Seeking.

In our study, we notice that $1.6 \%$ of subjects who responded to the CPGI have a problem with gambling (Table 2) of which majority of them are males ( $2.7 \%$ of boys who responded against $0.6 \%$ of girls). However, $3.2 \%$ are at moderate risk ( $4.6 \%$ of boys and $2 \%$ of girls) and $8.3 \%$ are at low risk of developing a gambling problem ( $8.5 \%$ of boys and $8.1 \%$ girls).

According to the different countries, we find significant differences in prevalence of gambling in adolescent populations. Young people (adolescents and young adults) have higher prevalence than adults with respect to problem and pathological gambling. This can be related to a broader phenomenon i.e. the frequency of risky behaviors during adolescence.

However, according to certain authors, describing pathological gambling as a "variable" than as "chronic" would be far more coherent to reality. This "lability" in terms of addictive gambling, could allow further perspective into the impact of epidemiological data; which reveals that adolescents have very high prevalence rates compared to adults. These data may reflect upon the existence of transient disorders in adolescents.

In terms of the link between the different facets of the UPPS and the CPGI, our results are quite mixed. The subjects with pathological gambling exhibited higher risk seeking and an immediate reward focus in the neuropsychological tests, and comparable strategic planning to the control group. Decision making impairments were related to more severe delay discounting and specifically, to increased urgency and less premeditation [41].

The urgency and premeditation are specifically related to disadvantageous decision-making and should be tackled in intervention strategies focusing on emotion tolerance and control strategies, specially for young. Worldwide literature reveals that the prevalence of gambling behaviours is significant in minor populations. A recent study of 994 Italian teenagers (average age $=16.57$ years) suggests that $91 \%$ of subjects have indulged in betting or gambling during the past year [16]. Several cross-sectional studies on the populations of 12 - 20 years, suggest that $60 \%$ to $99 \%$ of subjects have gambled in the past 12 months [42].

More moderate but equally important results suggest that $77 \%$ - $83 \%$ of adolescents are involved in gambling behaviours [4]. Our data demonstrates that the presence of gambling behaviour in our adolescent population is significantly lower than the international literature since $33 \%$ of our sample has reported having gambled at least once during their lifetime. 


\section{Limitations}

Our study has certain limitations. Firstly, the use of screening tools such as the CPGI may overestimate the percentage of pathological gambling [43]. This tool has not been developed for an adolescent population. However, our choice was motivated by the fact that the CPGI has been validated on the general population and has been used by INPES in the framework of the Baromètre Santé [5]. The CPGI allows greater distinction of subtypes of players and contributes to a clearer categorisation of players, ranging from low-risk gambling to problematic gambling.

Conditions in which the questionnaire was administered could have also been a hindrance to our study. Interviewed on a school day, the subjects were concerned about the confidentiality of their responses and also found the questionnaire to be long.

\section{Conclusions}

Gambling behaviour amongst adolescents is a reality despite it being legally banned. Although our data indicate low prevalence rate as compared to other countries, it must be taken into account to develop prevention campaigns at early age.

Impulsivity and more importantly the dimension of sensation seeking must be highlighted in prevention programs. However, it is also necessary to take into account cognitive distortions as well as social influence with respect to gambling while developing interventions in order to curb the problem of PG.

\section{Funding}

The study has received a grant from Française des Jeux (FDJ) and Pari Mutuel Urbain (PMU).

\section{Conflict of Interest}

The authors declare that they have no conflict of interest.

\section{References}

[1] Gupta, R. and Derevensky, J. (2001) An Examination of the Differential Coping Styles of Adolescents with Gambling Problems. Report to the Ministry of Health and Long-Term Care, McGill University, Montreal.

[2] Huang, J.H. and Boyer, R. (2007) Epidemiology of Youth Gambling Problems in Canada: A National Prevalence Study. Canadian Journal of Psychiatry, 52, 657-665.

[3] Hurt, H., Giannetta, J.M., Brodsky, N.L., Shera, D. and Romer, D. (2008) Gambling Initiation in Preadolescents. Journal of Adolescent Health, 43, 91-93. http://dx.doi.org/10.1016/j.jadohealth.2007.12.018

[4] Blinn-Pike, L., Worthy, S.L. and Jonkman, J. (2010) Adolescent Gambling: A Review of an Emerging Field of Research. Journal of Adolescent Health, 47, 223-236. http://dx.doi.org/10.1016/j.jadohealth.2010.05.003

[5] Observatoires Français des Drogues et des Toxicomanies et Inpes Baromètre Santé (2011) Les niveaux et pratiques des jeux de hasard et d'argent en 2010. Tendances, 77.

[6] Valleur, M. and Bucher, C. (1997) Le jeu pathologique. PUF, Paris.

[7] Fernandez, L., Bonnet, A. and Loonis, E. (2004) Quelles sont les nouvelles formes d'addiction ? Proteste, 100, 10-11.

[8] Bronnec, M., Rocher, B., Bouju, G. and Vénisse, J.L. (2010) Jeu et addiction. Annales Médico-Psychologiques, 168, 509-512. http://dx.doi.org/10.1016/j.amp.2010.06.004

[9] Shaffer, H.J. and Hall, M.N. (2001) Updating and Refining Prevalence Estimates of Disordered Gambling Behaviour in the United States and Canada. Canadian Journal of Public Health, 92, 168-172.

[10] Blinn-Pike, L., Worthy, S.L. and Jonkman, J.N. (2007) Disordered Gambling among College Students: A Meta-Analytic Synthesis. Journal of GamblingStudies, 23, 175-183. http://dx.doi.org/10.1007/s10899-006-9036-2

[11] Thor Olason, D., Sigurdardottir, K. and Smari, J. (2006) Prevalence Estimates of Gambling Participation and Problem Gambling among 16-18-Year-Old Students in Iceland: A Comparison of the SOGS-RA and DSM-IV-MR-J. Journal of Gambling Studies, 22, 23-39. http://dx.doi.org/10.1007/s10899-005-9001-5

[12] Fisher, S. (1999) A Prevalence Study of Gambling and Problem Gambling in British Adolescents. Addiction Research, 7, 509-538. http://dx.doi.org/10.3109/16066359909004403

[13] American Psychiatric Association (2013) Diagnostic and Statistical Manual of Mental Health Disorders: DSM-5. 5th 
Edition, American Psychiatric Publishing, Washington DC.

[14] Fisher, S. (1993) Gambling and Pathological Gambling in Adolescents. Journal of Gambling Studies, 9, 277-288.

[15] Ariyabuddhiphongs, V. (2013) Adolescent Gambling: A Narrative Review of Behavior and Its Predictors. International Journal of Mental Health \& Addiction, 11, 97-109. http://dx.doi.org/10.1007/s11469-012-9401-6

[16] Donati, M.A., Chiesi, F. and Primi, C. (2013) A Model to Explainat-Risk/Problemg Ambling among Male and Female Adolescents: Gender Similarities and Differences. Journal of Adolescence, 36, 129-137. http://dx.doi.org/10.1016/j.adolescence.2012.10.001

[17] Derevensky, J. and Gupta, R. (1999) Youth Gambling: A Clinical and Research Perspective. e-Gambling: The Electronic Journal of Gambling Issues, 2, 1-10.

[18] Jacobs, D.F. (2000) Juvenile Gambling in North America: An Analysis of Long Term Trends and Future Prospects. Journal of Gambling Studies, 16, 119-152. http://dx.doi.org/10.1023/A:1009476829902

[19] Shaffer, H.J. and Hall, M.N. (1996) Estimating Prevalence of Adolescent Gambling Disorders: A Quantitative Synthesis and Guide toward Standard Gambling Nomenclature. Journal of Gambling Studies, 12, 193-214. http://dx.doi.org/10.1007/BF01539174

[20] Grall-Bronnec, M., Bouju, G., Landréat-Guillou, M. and Vénisse, J.L. (2010) Evaluation Socio Démographique, Clinique et du Parcours de jeu d'un Echantillon de Joueurs Pathologiques Français. L'encéphale, 36, 452-460. http://dx.doi.org/10.1016/j.encep.2010.02.002

[21] Raisamo, S., Halme, J., Murto, A. and Lintonen, T. (2013) Gambling-Related Harms among Adolescents: A Population-Based Study. Journal of Gambling Studies, 29, 151-159. http://dx.doi.org/10.1007/s10899-012-9298-9

[22] Villella, C., Martinotti, G., Di Nicola, M., Cassano, M., La Torre, G., Gliubizzi, M.D., et al. (2001) Behavioural Addictions in Adolescents and Young Adults: Results from a Prevalence Study. Journal of Gambling Studies, 27, 203214. http://dx.doi.org/10.1007/s10899-010-9206-0

[23] Potenza, M.N., Steinberg, M.A., Skudlarski, P., Fulbright, R.K., Lacadie, C.M., Wilber, M.K. and Wexler, B.E. (2003) Gambling Urges in Pathological Gambling: A Functional Magnetic Resonance Imaging Study. Archives of General Psychiatry, 60, 828-836. http://dx.doi.org/10.1001/archpsyc.60.8.828

[24] Fuentes, D., Tavares, H., Artes, R. and Gorenstein, C. (2006) Self-Reported and Neuropsychological Measures of Impulsivity in Pathological Gambling. Journal of the International Neuropsychological Society, 12, 907-912. http://dx.doi.org/10.1017/S1355617706061091

[25] Krueger, T.H.C., Schedlowski, M. and Meyer, G. (2005) Cortisol and Heart Rate Measures during Casino Gambling in Relation to Impulsivity. Neuropsychobiology, 52, 206-211. http://dx.doi.org/10.1159/000089004

[26] MacKillop, J., Anderson, E.J., Castelda, B.A., Mattson, R.E. and Donovick, P.J. (2006) Convergent Validity of Measures of Cognitive Distortions, Impulsivity, and Time Perspective with Pathological Gambling. Psychology of Addictive Behaviors, 20, 75. http://dx.doi.org/10.1037/0893-164X.20.1.75

[27] Billieux, J., Rochat, L., Lien Rebetez, M.M. and Van der Linden, M. (2008) Are All Facets of Impulsivity Related to Self-Reported Compulsive Buying Behavior? Personality and Individual Differences, 44, 1432-1442. http://dx.doi.org/10.1016/j.paid.2007.12.011

[28] Michalczuk, R., Bowden-Jones, H., Verdejo-Garcia, A. and Clark, L. (2011) Impulsivity and Cognitive Distortions in Pathological Gamblers Attending the UK National Problem Gambling Clinic: A Preliminary Report. Psychological Medicine, 41, 2625-2635. http://dx.doi.org/10.1017/S003329171100095X

[29] MacKillop, J., Amlung, M.T., Few, L.R., Ray, L.A., Sweet, L.H. and Munafo, M.R. (2011) Delayed Reward Discounting and Addictive Behavior: A Meta-Analysis. Psychopharmacology, 216, 205-321. http://dx.doi.org/10.1007/s00213-011-2229-0

[30] Barratt, E.S. (1993) Impulsivity: Integrating Cognitive, Behavioral, Biological and Environmental Data. In: McCowan, W., Johnson, J. and Shure, M., Eds., The Impulsive Client: Theory, Research, and Treatment, American Psychological Association, Washington DC.

[31] Whiteside, S.P. and Lynam D.R. (2001) The Five Factor Model and Impulsivity: Using a Structural Model of Personality to Understand Impulsivity. Personality and Individual Differences, 30, 669-689. http://dx.doi.org/10.1016/S0191-8869(00)00064-7

[32] Cyders, M.A., Smith, G.T., Spillane, N.S., Fischer, S., Annus, A.M. and Peterson, C. (2007) Integration of Impulsivity and Positive Mood to Predictrisky Behavior: Development and Validation of a Measure of Positive Urgency. Psychological Assessment, 19, 107-118. http://dx.doi.org/10.1037/1040-3590.19.1.107

[33] Ferris, J. and Wynne, H. (2001) The Canadian Problem Gambling Index: Final Report. Canadian Center on Substance Abuse, Ottawa.

[34] Billieux, J., Rochat, L., Ceschi, G., Carré, A., Offerlin-Meyer, I., Delfeldre, A.C., Khazaal, Y., Besche-Richard, C. and 
Van der Linden, M. (2012) Validation of a Short French Version of the UPPS-P Impulsive Behavior Scale. Comprehensive Psychiatry, 53, 609-615. http://dx.doi.org/10.1016/j.comppsych.2011.09.001

[35] Van der Linden, M., d’Acremont, M., Zermatten, A., Jermann, F., Larøi, F., Willems, S., Juillerat, A.-C. and Bechara, A. (2006) A French Adaptation of the UPPS Impulsive Behavior Scale. European Journal of Psychological Assessment, 22, 38-42. http://dx.doi.org/10.1027/1015-5759.22.1.38

[36] Billieux, J., Gay, P., Rochat, L. and Van der Linden, M. (2010) The Role of Urgency and Its Underlying Psychological Mechanisms in Problematic Behaviours. Behaviourresearch and Therapy, 48, 1085-1096. http://dx.doi.org/10.1016/j.brat.2010.07.008

[37] Billieux, J., Van der Linden, M. and Ceschi, G. (2007) Which Dimensions of Impulsivity Are Related to Cigarette Craving? Addictive Behaviors, 32, 1189-1199. http://dx.doi.org/10.1016/j.addbeh.2006.08.007

[38] Linnet, J., Rojskjaer, S., Nygaard, J. and Maher, B.A. (2006) Episodic Chasing in Pathological Gamblers Using the Iowa Gambling Task. Scandinavian Journal of Psychology, 47, 43-49. http://dx.doi.org/10.1111/j.1467-9450.2006.00491.x

[39] Martinotti, G., Andreoli, S., Giametta, E., Poli, V., Bria, P. and Janiri, L. (2006) The Dimensional Assessment of Personality in Pathologic and Social Gamblers: The Role of Novelty Seeking and Self-Transcendence. Comprehensive Psychiatry, 47, 350-356. http://dx.doi.org/10.1016/j.comppsych.2005.12.005

[40] Valleur, M. and Matysiak, J.C. (2006) Les Addictions: Panorama Clinique, Modèles Explicatifs, Débat Social et Prise en Charge. Armand Colin, Paris.

[41] Kräplin, A., Dshemuchadse, M., Behrendt, S., Scherbaum, S., Goschke, T. and Bühringer, G. (2014) Dysfunctional Decision-Making in Pathological Gambling: Pattern Specificity and the Role of Impulsivity. Psychiatry Research, 215, 675-682. http://dx.doi.org/10.1016/j.psychres.2013.12.041

[42] Splevins, K., Mireskandari, S., Clayton, K. and Blaszczynski, A. (2010) Prevalence of Adolescent Problem Gambling, Related Harms and Help-Seeking Behaviours among an Australian Population. Journal of GamblingStudies, 26, 189204. http://dx.doi.org/10.1007/s10899-009-9169-1

[43] McCready, J. and Adlaf, E. (2006) Performance and Enhancement of the Canadian Problem Gambling Index (CPGI): Report and Recommendations. Healthy Horizons Consulting. 
Scientific Research Publishing (SCIRP) is one of the largest Open Access journal publishers. It is currently publishing more than 200 open access, online, peer-reviewed journals covering a wide range of academic disciplines. SCIRP serves the worldwide academic communities and contributes to the progress and application of science with its publication.

Other selected journals from SCIRP are listed as below. Submit your manuscript to us via either submit@scirp.org or Online Submission Portal.
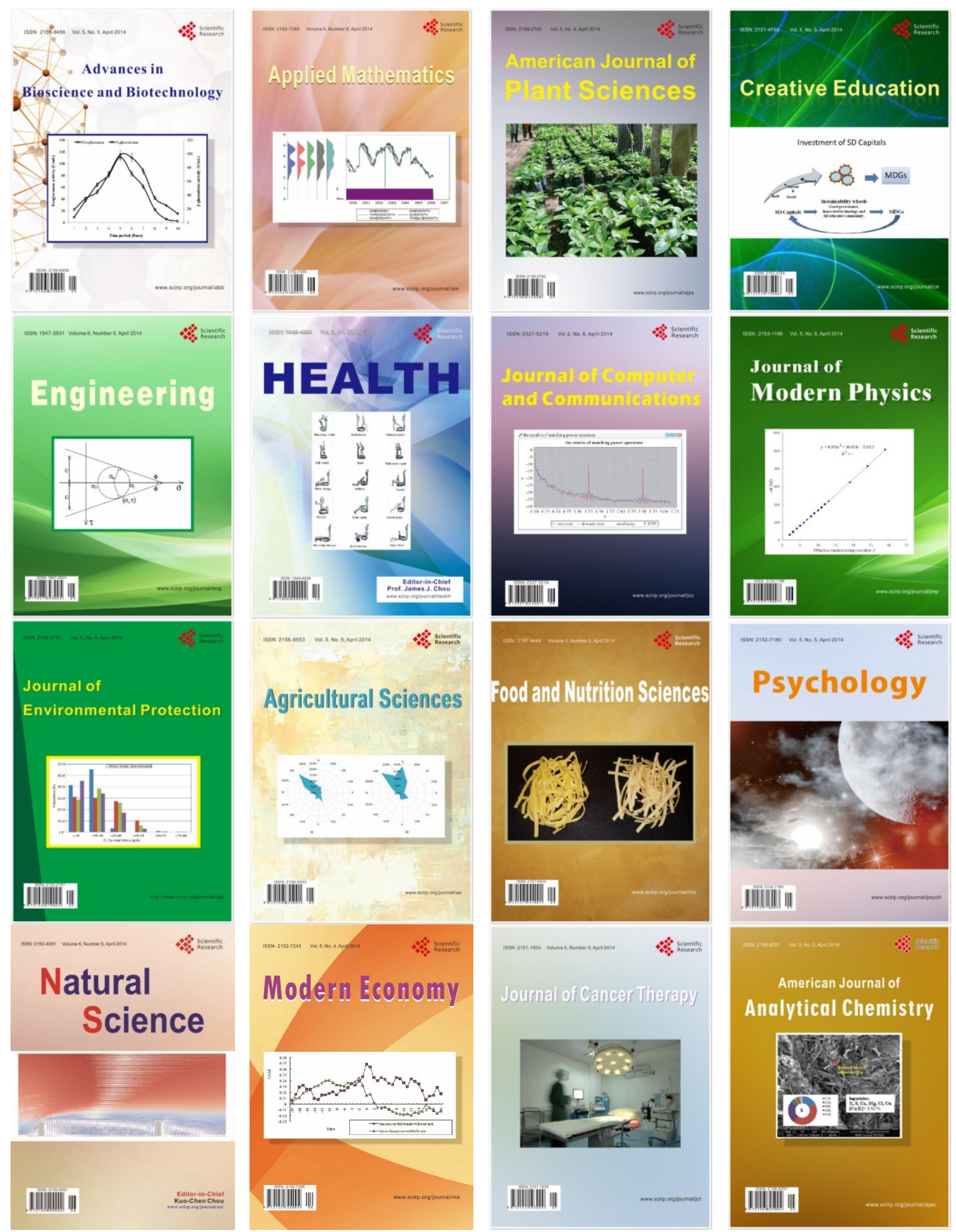